\title{
Computational Investigation and Screening of High-Energy-Density Materials: Based on Nitrogen-Rich 1,2,4,5-tetrazine Energetic Derivatives
}

\author{
Lian Zeng ${ }^{1}$, Yuhe Jiang ${ }^{1}$, Jinting $\mathrm{Wu}^{1}$, Hongbo $\mathrm{Li}^{1}$, and Jianguo Zhang ${ }^{2}$ \\ ${ }^{1}$ Southwest University of Science and Technology \\ ${ }^{2}$ Beijing Institute of Technology
}

March 19, 2021

\begin{abstract}
Abstract: In the present work, the geometric structures, the frontier molecular orbitals and the enthalpy of formation (HOF) of thirty six 1, 2, 4, 5-tetrazine derivatives (FTT) were systematically studied by using the B3LYP/6-311+G* method of density functional theory. Meanwhile, we also predicted the stability, detonation properties and thermodynamic properties of all FTT compounds. Results showed that all compounds have superior enthalpy of formation far exceeding that of common explosives RDX and HMX, ranging from $859 \mathrm{~kJ} \cdot \mathrm{mol}-1-1532 \mathrm{~kJ} \cdot \mathrm{mol}-1$. In addition, the detonation performance $(\mathrm{Q}=1426 \mathrm{cal} \cdot \mathrm{g}-1$-1804cal.g$1 ; \mathrm{P}=29.54 \mathrm{GPa}-41.84 \mathrm{GPa} ; \mathrm{D}=8.02 \mathrm{~km} \cdot \mathrm{s}-1-9.53 \mathrm{~km} \cdot \mathrm{s}-1)$, which is superior to TATB and TNT. It is also concluded that the introduction of coordination oxygen on the tetrazine ring can improve the HOF, density and detonation performance of the title compound, and -NH-NH- bridge and -NHNO2 group are also the perfect combination to increase these values. In view of stability, because of the fascinating performance of D3 $(\rho=1.89 \mathrm{~g} \cdot \mathrm{cm}-3 ; \mathrm{D}=9.38 \mathrm{~km} \cdot \mathrm{s}-1 ; \mathrm{P}=40.13 \mathrm{GPa}), \mathrm{E} 3(\rho=1.87 \mathrm{~g} \cdot \mathrm{cm}-3 ; \mathrm{D}$ $=9.19 \mathrm{~km} \cdot \mathrm{s}-1 ; \mathrm{P}=38.35 \mathrm{GPa}), \mathrm{F} 1(\rho=1.87 \mathrm{~g} \cdot \mathrm{cm}-3 ; \mathrm{D}=9.42 \mathrm{~km} \cdot \mathrm{s}-1 ; \mathrm{P}=40.23 \mathrm{GPa})$ and $\mathrm{F} 3(\rho=1.92 \mathrm{~g} \cdot \mathrm{cm}-3 ; \mathrm{D}=9.53 \mathrm{~km} \cdot \mathrm{s}-1 ;$ $\mathrm{P}=41.84 \mathrm{GPa})$, makes them very attractive to be chosen as HEDMs.
\end{abstract}

\section{Hosted file}

manuscripts.pdf available at https://authorea.com/users/298692/articles/514355-computationalinvestigation-and-screening-of-high-energy-density-materials-based-on-nitrogen-rich-1-24-5-tetrazine-energetic-derivatives 